\title{
In pursuit of a better broiler: a comparison of the inactivity, behavior, and enrichment use of fast- and slower growing broiler chickens
}

\author{
Lauren C. Dawson ${ }^{\circledR},{ }^{*}, \dagger, 1$ Tina M. Widowski, ${ }^{*}{ }^{\dagger}$ Zhenzhen Liu, ${ }^{*, \dagger}$ A. Michelle Edwards ${ }^{\oplus},{ }^{\ddagger}$ and \\ Stephanie Torrey ${ }^{*} \dagger$ \\ ${ }^{*}$ Department of Animal Biosciences, University of Guelph, Guelph ON, Canada; ${ }^{\dagger}$ Campbell Centre for the Study of \\ Animal Welfare, University of Guelph, Guelph ON, Canada; and ${ }^{\ddagger}$ Ontario Agricultural College, University of Guelph, \\ Guelph ON, Canada
}

\begin{abstract}
Selection for rapid growth has produced heavier, more efficient broiler chickens, but has also introduced health and welfare issues, which may cause or be caused by inactivity. Rapid growth may also limit the performance of motivated behaviors, whereas the provision of enrichment may increase these behaviors and general activity. This study aimed to evaluate the inactivity, behavior patterns, and enrichment use of 2 fast- (CONV) and 12 slower growing broiler strains (categorized as fastest [FAST], moderate [MOD], and slowest slow [SLOW]), based on their growth rates; 4 strains/category]. To evaluate inactivity, one male and one female from 153 pens were outfitted with omnidirectional accelerometers from d 21 until processing (14 -24 birds/strain from 8 to 12 pens/strain). Additionally, to supplement inactivity data, 5-min continuous behavioral observations of four focal birds per pen (2 males, 2 females) were conducted on days 26,42 , and 56 (72-148 observations of 8-12 pens/strain) to quantify the duration and frequency of various behaviors; at the
\end{abstract}

same time, 5 to 11 instantaneous scan samples were also performed for pen-based enrichment use. Inactivity peaked at 78 to $80 \%$ of the day for all strains; however, those with slower growth rates reached these levels at older ages. Compared to slower growing strains at the same age, faster growing strains were more inactive, spent more time sitting and feeding, spent less time standing and walking, and used enrichments less; these differences mostly occurred at younger ages. Generally, at the same age, strains with similar growth rates (within the same category) behaved similarly, with only a few exceptions. Results suggest that not all strains identified as "slow-growing" broilers behave differently from fast-growing broilers, nor do they all behave similarly to each other. As such, results suggest that improved broiler welfare, particularly with respect to reduced inactivity, the performance of a wider range of normal, motivated behaviors, and/or increased enrichment use, is related to the broiler strain's specific growth rate.

Key words: broiler, welfare, inactivity, behavior, slow-growing

2021 Poultry Science 100:101451 https://doi.org/10.1016/j.psj.2021.101451

\section{INTRODUCTION}

Due to genetic selection for rapid growth and advances in management practices, modern broiler chickens now reach market weight $(>2 \mathrm{~kg})$ in as little as $6 \mathrm{wk}$. In comparison to broiler chickens from the 1950s, current commercial broilers have higher body weights, increased breast yields, and improved feed conversion ratios (Havenstein et al., 2003a,b; Zuidhof et al., 2014). These improvements in production and efficiency,

(C) 2021 The Authors. Published by Elsevier Inc. on behalf of Poultry Science Association Inc. This is an open access article under the CC BY-NC-ND license (http://creativecommons.org/licenses/by-nc-nd/ $4.0 /)$.

Received May 14, 2021.

Accepted August 26, 2021.

${ }^{1}$ Corresponding author: dawsonl@uoguelph.ca however, come at a cost to broiler health and welfare. Modern broilers have poorer immune system function (Cheema et al., 2003) and higher mortality rates (Havenstein et al., 2003a). Rapid growth is also associated with increased incidences of metabolic disorders (Bessi, 2006), muscle myopathies (e.g., white striping, woody breast; Kuttappan et al., 2016), skeletal disorders (e.g., varus/valgus deformities [Shim et al., 2012], tibial dyschondroplasia [TD; Fanatico et al., 2008; Shim et al., 2012]), and lameness (Kestin et al., 2001; Wilhelmsson et al., 2019).

Fast-growing ("conventional") broilers also have low activity levels. Broilers can spend as much as 70 to $80 \%$ of their day sitting (Bizeray et al., 2000; Weeks et al., 2000; Bokkers and Koene, 2003; Dixon, 2020), whereas their ancestors, red junglefowl, spend as little as $10 \%$ of their day sitting (Dawkins, 1989). Low locomotor 
activity, or inactivity, is not a welfare concern in and of itself; however, inactivity may cause or be caused by broiler welfare issues. For one, low activity is linked to poor leg health and lameness. Physical exercise improves bone development and health, and reduces deformities (Reiter and Bessei, 1998, 2011), whereas a lack of exercise may lead to a higher incidence of leg deformities (Haye and Simons, 1978). Based on lame broilers' behavioral responses to analgesics (McGeown et al., 1999; Danbury et al., 2000), lameness is painful, so broilers who become lame due to a lack of exercise are likely to further decrease their activity, including altering their feeding and drinking behavior, and the performance of motivated behaviors. Low activity is also linked to contact dermatitis. Low locomotor activity implies an increased duration of time sitting or lying in contact with potentially poor quality litter, which increases the incidence of contact dermatitis (i.e., footpad dermatitis, hock burn; Bassler et al., 2013; De Jong et al., 2014). The lesions associated with contact dermatitis are also thought to be painful (Bessei, 2006; Haslam et al., 2006).

Beyond general inactivity, the specific behaviors that broilers perform, in terms of both the duration of time spent performing them and the frequency with which they are performed may also be altered by their growth rate. For example, in addition to differences in sitting, fast- and slower growing broilers also differ in the time they spend standing, walking, feeding, drinking, and performing exploratory behavior (Bizeray et al., 2000; Bokkers and Koene, 2003; Wallenbeck et al., 2016; Dixon, 2020). Broilers' heavy body weight and/or conformation may also prevent their engagement in normal behaviors, or prevent the performance of other behaviors that broilers are motivated to perform, such as perching or dustbathing (Bokkers and Koene, 2003; Wallenbeck et al., 2016; Dixon, 2020). Altogether, if broilers are unable to perform normal, highly motivated behaviors, they may become frustrated (Bradshaw et al., 2002; Bokkers et al., 2007).

The provision of environmental enrichment may improve broiler welfare by increasing activity, while also providing an opportunity for the expression of a wider range of normal, motivated behaviors (e.g., Bizeray et al., 2002; Bach et al., 2019; Vasdal et al., 2019). Elevated platforms allow for elevated resting, a natural behavior for junglefowl, and their provision has been linked to improved walking ability (i.e., better gait scores; Kaukonen et al., 2017), and lower incidences of TD (Kaukonen et al., 2017) and footpad dermatitis (Tahamtani et al., 2020). Elevated platforms may also increase useable space while reducing time in contact with the litter (Bizeray et al., 2002), improve thermoregulation (Riber et al., 2018), reduce fearfulness (Tahamtani et al., 2018), and increase the performance of comfort behaviors (i.e., dustbathing, preening, stretching; Bach et al., 2019). Additionally, oral enrichment objects (e.g., hanging strings, straw bales) increase the opportunity for pecking and foraging, and have also been linked to improved gait scores (Bailie and O'Connell, 2015) and longer latencies to lie (Bailie et al., 2013).

Given the welfare issues associated with rapid growth, there has been increasing interest in the potential of using slower growing broiler strains for commercial production. Although previous studies have evaluated the welfare or welfare-related outcomes of fast- and slower growing broilers (e.g., Bokkers and Koene, 2003; Fanatico et al., 2005; Lichovníková et al., 2017; Wilhelmsson et al., 2019; Dixon, 2020; Mancinelli et al., 2020; Weimer et al., 2020), many of these studies directly compared a limited number of strains (e.g., 1 conventional vs. 1 slower growing strain: Bokkers and Koene, 2003; Wallenbeck et al., 2016; Lichovníková et al., 2017; Wilhelmsson et al., 2019; Weimer et al., 2020), evaluated welfare in nonintensive settings (e.g., Fanatico et al., 2005; Mancinelli et al., 2020), and/or evaluated slower growing birds at comparably low body weights (e.g., <2 kg: Bokkers and Koene, 2003; Lichovníková et al., 2017). Additionally, even among strains considered to be slower growing, there is a large range in growth rates and no consensus about growth rate cut-offs that ensure or lead to improved welfare.

Our goal was to benchmark the welfare of broiler chickens with different growth rates, including various degrees of slow growth, raised to similar body weights under the same management and housing conditions. To do so, we developed a large scale, multioutcome study designed to evaluate the effects of both age and body weight on the welfare outcomes of 2 conventional and 12 slower growing broiler strains. Differences in efficiency and mortality are available in Torrey et al. (2021). This paper presents the results of a subsection of the larger study, with a focus on behavioral measures of welfare. More specifically, across 14 strains of conventional and slower growing broilers, we aimed to monitor and compare inactivity levels using accelerometers, assess differences in the durations and frequencies of behaviors via live observations, and compare enrichment use using scan sampling, at both the same age and similar body weights.

\section{MATERIALS AND METHODS Animals, Management, and Housing}

Animal use was approved by the University of Guelph Animal Care Committee (Animal Utilization Protocol \#3746). This study encompasses a subsection of a largescale study to investigate behavioral, physiological, and production differences between conventional (fast-growing) and slower growing broiler strains. A full description of the animals, management, and housing is available in Torrey et al. (2021).

In short, the study followed a randomized incomplete block design, with 8 trials and up to 28 pens per trial. All pens were in the same room at the Arkell Poultry Research Facility (Guelph, ON, Canada), and this room was used for all trials. Pens were divided into 4 blocks according to location to account for differences in 
microclimate within the room. In total, 14 broiler strains were tested: 2 conventional (strains B and C; $\mathrm{ADG}_{0-47}=66.0-68.7 \mathrm{~g} /$ day) and 12 slower growing strains (strains D-K, M-O, and S; $\mathrm{ADG}_{0-61}=43.6-55.5$ $\mathrm{g} /$ day). Each strain was assessed in up to 3 trials, in 4 pens per trial, and in 1 pen per block per trial.

All strains were raised under similar conditions: in a $238 \times 160 \mathrm{~cm}$ pen with softwood shavings as litter, 5 nipple drinkers, and a hanging feeder with ad libitum feed formulated for slow growth. Pens were enriched with a 30 -cm high platform with a $25^{\circ}$ ramp, a hanging scale, one-fourth of a PECKstone mineral block (Protekta, Lucknow, Ontario, Canada), and a hanging nylon rope with strips of polyester cloth tied to the end. Broilers were placed in pens of 44 birds ( 22 females, 22 males) on day of hatch. Light intensity was kept at 20 lux. To assess the impact of both age and weight, strains were processed at different ages, according to breeders' expected time to reach one of 2 target weights ( $\mathbf{T W}$ ): $2.1 \mathrm{~kg}(\mathrm{TW} 1)$ or $3.2 \mathrm{~kg}$ (TW 2). Conventional strains were processed at d 34 (TW 1) or d 48 ( TW 2) and slower growing strains were processed at d 48 (TW 1) or d 62 (TW 2). On d 34, remaining pens (those that had not been processed) with conventional and slower growing strains were reduced to 38 and 42 birds, respectively, and on d 48, remaining pens with slower growing strains were reduced to 38 birds to maintain a stocking density of $30 \mathrm{~kg} / \mathrm{m}^{2}$.

\section{Inactivity Measurement}

Actical (Philips Respironics, Murrysville, PA) accelerometers were used to continuously assess broiler activity. Actical accelerometers are small $(28 \times 27 \times 10 \mathrm{~mm})$ and lightweight $(17.5 \mathrm{~g})$, with a sensitivity of 0.05 to $2 \mathrm{G}$ and frequency of 0.35 to $3.5 \mathrm{~Hz}$. They are multidirectional piezoelectric sensor accelerometers that can detect movement along any axis, accounting for both the intensity and duration of movement. These specific accelerometers have been used to assess activity in a number of species (e.g., laying hens [Casey-Trott and Widowski, 2018], dairy cattle [Rialland et al., 2014], cats [Lascelles et al., 2008; de Godoy and Shoveller, 2017]) and have been validated for assessing inactivity in laying hens (Casey-Trott and Widowski, 2018). Acticals were programmed as follows: epoch length: $1 \mathrm{~s}$; subject height: $10.0 \mathrm{~cm}$; subject weight $0.5 \mathrm{~kg}$; subject sex: female; subject age: 2 ; these settings maximize sensitivity for activity detection in laying hens (Casey-Trott and Widowski, 2018).

At $21 \mathrm{~d}$ of age, one male and one female bird per pen were outfitted with an Actical accelerometer; at this age, the device weighed less than $5 \%$ of the body weight of birds from all strains, per the recommendation of Siegford et al. (2016) for wearable equipment. Moreover, weight-matched broilers with and without Actical devices installed behave similarly during mobility tests, suggesting that their use does not affect broiler behavior (Liu, 2019). Birds were randomly selected from 12 sentinel birds (that were selected and wing tagged at hatch) and were not subject to any other live testing, other than behavioral observations. Acticals were attached as "backpacks" using beige-colored cotton elastic material that was looped through the device and around the birds' wings, with 2 fingers' worth of space between the strap and wing. Straps were checked every few days and adjusted as needed to ensure that they did not affect circulation or movement. Chickens wore the accelerometers continuously until the day prior to processing.

Activity data was downloaded from the Actical devices using Actical 3.10 software (Koninklijke Philips N. V., Amsterdam, the Netherlands). Using SAS 9.4, the number of 15 -s epochs with no activity counts (0 acceleration registered) was summed per day to calculate daily inactivity counts for each bird. The day of installation and removal were excluded from analysis to avoid including incomplete data.

Data from 153 pens, accounting for 138 males and 142 females, were analyzed. CONV were represented in 20 pens, FAST in 42 pens, MOD in 47 pens, and SLOW in 44 pens (see below for definitions). Each strain was represented by 14 to 24 birds in 8 to 12 pens.

\section{Behavioral Observations}

On d 26 (all strains), 42 (all strains), and 56 (slower growing strains only), behavioral observations were conducted on four focal birds per pen ( 2 males, 2 females, including the 2 birds outfitted with an Actical accelerometer, all selected from the 12 sentinel birds selected at hatch and identified with livestock marker). Observations were made according to the ethogram outlined in Supplementary Table 1 (see Table 1 for a simplified version). All occurrences of each state and event behavior, as well as the location in which they occurred, were recorded using The Pocket Observer v3.2.43 (Noldus Information Technology, Wageningen, the Netherlands)

Table 1. Simplified ethogram for live behavioral observations.

\begin{tabular}{|c|c|}
\hline Behavior & Description \\
\hline \multicolumn{2}{|l|}{ State } \\
\hline Sitting & $\begin{array}{l}\text { Immobile, with entire breast touching the ground. Does } \\
\text { not include sitting while engaged in other types of } \\
\text { behavior (e.g., excludes sidelying, feeding while sitting). }\end{array}$ \\
\hline Standing & $\begin{array}{l}\text { Immobile while supported on both legs, body not touching } \\
\text { the ground. Does not include standing while engaged in } \\
\text { other types of behavior (e.g., excludes feeding while } \\
\text { standing, foraging). }\end{array}$ \\
\hline Walking & $\begin{array}{l}\text { Slow forward movement, using legs. Does not include } \\
\text { other types of locomotion such as running, wing-assisted } \\
\text { running or play fighting. }\end{array}$ \\
\hline Feeding & Downward pecking in feeder while standing or sitting. \\
\hline Drinking & Pecking at nipple drinker. \\
\hline Preening & $\begin{array}{l}\text { Moving the beak through the feathers while standing, side- } \\
\text { lying, or sitting. }\end{array}$ \\
\hline \multicolumn{2}{|r|}{ 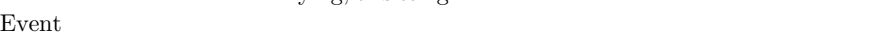 } \\
\hline Pecking litter & Peck at litter, no ground scratching involved. \\
\hline Leg stretching & $\begin{array}{l}\text { Stretching one of the legs while standing (sometimes } \\
\text { accompanied by wing stretching). }\end{array}$ \\
\hline \multicolumn{2}{|r|}{ 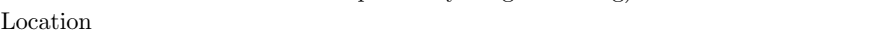 } \\
\hline On litter & On the litter, in any location other than those listed above. \\
\hline
\end{tabular}


on a Samsung Galaxy Tab4 tablet (Seoul, South Korea). Each focal bird was observed continuously for $5 \mathrm{~min}$, and all 4 birds per pen were successively and systematically observed to reduce bias toward activity. Observations took place between $08 \mathrm{~h} 00$ and $14 \mathrm{~h} 30$. All observers ( $\mathrm{n}=10$ total across the different trials) were trained and had acceptable interobserver reliability (kappa $>0.60$; McHugh, 2012). When multiple observers were used on the same day, each observer watched all pens within a block(s) to ensure that no single observer assessed all the pens of one strain.

The total duration spent performing each state behavior and the time spent in each location, as proportions of the total observation time, the number of bouts of each state behavior and the sum frequency of each event behavior were compiled. Many behaviors were performed in a small number of observations, and only behaviors that occurred in $\geq 20 \%$ of all observations were analyzed statistically; these behaviors were sitting, standing, walking, feeding (feed standing + feed sitting), drinking, and preening (preen standing + preen sidelying + preen sitting). With respect to location, on the litter (on litter + under platform/ramp) was the only location that occurred frequently enough to be analyzed; it was assessed in terms of duration only. Moreover, the total duration spent sitting in any capacity ("all sitting" = sitting + feed sitting + preen sitting), standing in any capacity ("all standing" = standing + feed standing + preen standing + drinking), in locomotion (walking + running + wing-assisted running), engaging in any behavior in which the chicken was off their feet ("off feet" = all sitting + sidelying + preen sidelying + dustbathing) and on their feet ("on feet" = all standing + locomotion + playfighting + foraging) were also calculated for analysis.

A total of 1,631 observations were analyzed, amounting to 678,640 , and 313 observations at d 26, 42, and 56, respectively. Analysis included data from 622 individual birds and 164 pens. Each strain was represented by 72 to 148 observations of 32 to 56 birds in 8 to 12 pens. Sample sizes for each category at each age or TW are outlined in Tables 2 and 3, respectively.

\section{Enrichment Use}

Prior to the behavioral observation of each pen (at 20-25 min intervals), an observer performed an instantaneous scan of their block(s) of observation pens to assess the number of birds on the platform, on the ramp, under the platform or ramp, on the scale, on the pecking stone, pecking the pecking stone, and pecking the rope. Locations were assigned based on the location of the chicken's 2 feet (e.g., both feet on the ramp = on the ramp) and/or the location of the majority of the body (e.g., $>50 \%$ under the platform $=$ under the platform). A minimum of 5 scans were performed of each pen on each observation day, by the same observer who had conducted the behavioral observations for that pen. Since scans were performed prior to each observation, the number of scans performed on any given day varied with the number of occupied pens in the room and the number of observers performing observations on that day; however, across the whole study, the mean number of scans was approximately the same for all strains. On a pen basis, the proportion of birds engaged in the use of

Table 2. Number of bouts (back-transformed LS-means \pm SEM) of sitting, standing, walking, feeding, drinking, and preening, as well as number of events of pecking litter and leg stretching, as assessed over a 300-s live observation period, by category at the same age.

\begin{tabular}{|c|c|c|c|c|}
\hline & $\mathrm{CONV}$ & FAST & MOD & SLOW \\
\hline D 26 & $(\mathrm{n}=104)$ & $(\mathrm{n}=180)$ & $(\mathrm{n}=196)$ & $(\mathrm{n}=198)$ \\
\hline Sitting & $1.21 \pm 0.08$ & $1.14 \pm 0.06$ & $1.32 \pm 0.06$ & $1.21 \pm 0.06$ \\
\hline Standing & $3.15 \pm 0.71^{\mathrm{a}}$ & $5.70 \pm 0.60^{\mathrm{b}}$ & $6.06 \pm 0.59^{\mathrm{b}}$ & $5.76 \pm 0.58^{\mathrm{b}}$ \\
\hline Walking & $2.19 \pm 0.29^{\mathrm{a}}$ & $3.72 \pm 0.30^{\mathrm{b}}$ & $4.06 \pm 0.32^{\mathrm{b}}$ & $3.63 \pm 0.28^{\mathrm{b}}$ \\
\hline Feeding & $0.68 \pm 0.12$ & $0.51 \pm 0.10$ & $0.38 \pm 0.10$ & $0.44 \pm 0.09$ \\
\hline Drinking & $1.02 \pm 0.50$ & $1.71 \pm 0.41$ & $1.57 \pm 0.41$ & $1.54 \pm 0.40$ \\
\hline Preening & $1.81 \pm 0.27^{\mathrm{a}}$ & $2.10 \pm 0.22^{\mathrm{ab}}$ & $2.68 \pm 0.22^{\mathrm{b}}$ & $2.51 \pm 0.21^{\mathrm{ab}}$ \\
\hline Pecking litter & $3.27 \pm 1.78$ & $8.51 \pm 1.45$ & $6.02 \pm 1.43$ & $5.95 \pm 1.38$ \\
\hline Leg stretching & $0.21 \pm 0.06^{\mathrm{a}}$ & $0.49 \pm 0.08^{\mathrm{b}}$ & $0.46 \pm 0.08^{\mathrm{b}}$ & $0.39 \pm 0.06^{\mathrm{ab}}$ \\
\hline D 42 & $(\mathrm{n}=64)$ & $(\mathrm{n}=179)$ & $(\mathrm{n}=199)$ & $(\mathrm{n}=198)$ \\
\hline Sitting & $0.91 \pm 0.10$ & $1.03 \pm 0.07$ & $1.02 \pm 0.06$ & $1.11 \pm 0.06$ \\
\hline Standing & $2.13 \pm 0.92^{\mathrm{a}}$ & $4.15 \pm 0.63^{\mathrm{ab}}$ & $5.06 \pm 0.59^{\mathrm{b}}$ & $5.20 \pm 0.60^{\mathrm{b}}$ \\
\hline Walking & $1.36 \pm 0.30^{\mathrm{a}}$ & $2.13 \pm 0.22^{\mathrm{ab}}$ & $2.78 \pm 0.24^{\mathrm{ab}}$ & $3.11 \pm 0.26^{\mathrm{b}}$ \\
\hline Feeding & $0.61 \pm 0.17$ & $0.28 \pm 0.10$ & $0.33 \pm 0.09$ & $0.37 \pm 0.10$ \\
\hline Drinking & $1.21 \pm 0.65$ & $1.53 \pm 0.43$ & $1.88 \pm 0.40$ & $1.64 \pm 0.41$ \\
\hline Preening & $1.13 \pm 0.35$ & $1.72 \pm 0.24$ & $1.67 \pm 0.22$ & $1.75 \pm 0.22$ \\
\hline Pecking litter & $3.34 \pm 2.39$ & $3.67 \pm 1.52$ & $6.16 \pm 1.41$ & $5.83 \pm 1.43$ \\
\hline Leg stretching & $0.32 \pm 0.11$ & $0.19 \pm 0.05$ & $0.30 \pm 0.06$ & $0.30 \pm 0.06$ \\
\hline D 56 & & $(\mathrm{n}=99)$ & $(\mathrm{n}=105)$ & $(\mathrm{n}=109)$ \\
\hline Sitting & - & $0.94 \pm 0.08$ & $0.99 \pm 0.08$ & $0.90 \pm 0.08$ \\
\hline Standing & - & $3.22 \pm 0.44$ & $3.22 \pm 0.45$ & $3.83 \pm 0.49$ \\
\hline Walking & - & $1.64 \pm 0.23$ & $1.63 \pm 0.24$ & $2.07 \pm 0.28$ \\
\hline Feeding & - & $0.45 \pm 0.15$ & $0.44 \pm 0.16$ & $0.48 \pm 0.16$ \\
\hline Drinking & - & $1.05 \pm 0.34$ & $1.12 \pm 0.30$ & $0.89 \pm 0.28$ \\
\hline Preening & - & $1.19 \pm 0.30$ & $1.49 \pm 0.32$ & $1.95 \pm 0.31$ \\
\hline Pecking litter & - & $6.25 \pm 2.22$ & $6.55 \pm 2.36$ & $7.32 \pm 2.32$ \\
\hline Leg stretching & - & $0.22 \pm 0.06$ & $0.22 \pm 0.06$ & $0.28 \pm 0.06$ \\
\hline
\end{tabular}

\footnotetext{
${ }^{\mathrm{ab}}$ Within row, values with no common superscript differ at adj. $P<0.05$.
} 
Table 3. Number of bouts (back-transformed LS-means \pm SEM) of sitting, standing, walking, feeding, drinking, and preening, as well as number of events of pecking litter and leg stretching, as assessed over a 300-s live observation period, by category at similar target weights.

\begin{tabular}{|c|c|c|c|c|}
\hline & CONV & FAST & MOD & SLOW \\
\hline Target weight $1(\mathrm{~kg})$ & $1.84(\mathrm{n}=104)$ & $2.37(\mathrm{n}=179)$ & $2.34(\mathrm{n}=199)$ & $1.94(\mathrm{n}=198)$ \\
\hline Sitting & $1.17 \pm 0.07$ & $1.03 \pm 0.06$ & $1.01 \pm 0.06$ & $1.11 \pm 0.06$ \\
\hline Standing & $3.10 \pm 0.64^{\mathrm{a}}$ & $3.99 \pm 0.62^{\mathrm{ab}}$ & $4.94 \pm 0.59^{\mathrm{b}}$ & $5.07 \pm 0.59^{\mathrm{b}}$ \\
\hline Walking & $1.95 \pm 0.32^{\mathrm{ab}}$ & $1.86 \pm 0.30^{\mathrm{a}}$ & $2.42 \pm 0.36^{\mathrm{ab}}$ & $2.72 \pm 0.40^{\mathrm{b}}$ \\
\hline Feeding & $0.68 \pm 0.15$ & $0.26 \pm 0.14$ & $0.29 \pm 0.13$ & $0.32 \pm 0.09$ \\
\hline Drinking & $1.01 \pm 0.54$ & $1.62 \pm 0.52$ & $1.81 \pm 0.50$ & $1.76 \pm 0.50$ \\
\hline Preening & $1.66 \pm 0.25$ & $1.53 \pm 0.23$ & $1.50 \pm 0.21$ & $1.51 \pm 0.21$ \\
\hline Pecking litter & $3.05 \pm 1.64$ & $3.01 \pm 1.54$ & $6.33 \pm 1.48$ & $5.75 \pm 1.47$ \\
\hline Leg stretching & $0.23 \pm 0.06$ & $0.20 \pm 0.06$ & $0.31 \pm 0.06$ & $0.29 \pm 0.06$ \\
\hline Target weight $2(\mathrm{~kg})$ & $3.20(\mathrm{n}=64)$ & $3.13(\mathrm{n}=99)$ & $3.17(\mathrm{n}=105)$ & $2.82(\mathrm{n}=109)$ \\
\hline Sitting & $0.97 \pm 0.09$ & $0.91 \pm 0.07$ & $0.98 \pm 0.07$ & $0.89 \pm 0.07$ \\
\hline Standing & $2.22 \pm 0.85$ & $3.52 \pm 0.72$ & $3.50 \pm 0.70$ & $4.22 \pm 0.71$ \\
\hline Walking & $1.23 \pm 0.29$ & $1.55 \pm 0.29$ & $1.52 \pm 0.28$ & $1.92 \pm 0.33$ \\
\hline Feeding & $0.52 \pm 0.19$ & $0.50 \pm 0.16$ & $0.44 \pm 0.16$ & $0.50 \pm 0.16$ \\
\hline Drinking & $1.31 \pm 0.67$ & $1.49 \pm 0.59$ & $1.52 \pm 0.58$ & $1.32 \pm 0.58$ \\
\hline Preening & $1.04 \pm 0.24^{\mathrm{ab}}$ & $1.01 \pm 0.20^{\mathrm{a}}$ & $1.48 \pm 0.24^{\mathrm{ab}}$ & $1.74 \pm 0.28^{\mathrm{b}}$ \\
\hline Pecking litter & $2.83 \pm 2.27$ & $6.20 \pm 1.86$ & $5.38 \pm 1.84$ & $6.81 \pm 1.81$ \\
\hline Leg stretching & $0.29 \pm 0.09$ & $0.22 \pm 0.07$ & $0.20 \pm 0.07$ & $0.26 \pm 0.07$ \\
\hline
\end{tabular}

${ }^{\mathrm{ab}}$ Within row, values with no common superscript differ at adj. $P<0.05$. At target weight $1, \mathrm{CONV}$ were $26 \mathrm{~d}$ of age, whereas the other strains were 42 $\mathrm{d}$ of age. At target weight 2, CONV were $42 \mathrm{~d}$ of age whereas the other strains were $56 \mathrm{~d}$ of age. Mean body weight (kg) within category is displayed.

each enrichment was calculated. Additionally, the proportion of birds using any enrichment (sum of all enrichment use), as well as the proportion of birds on the litter (total number of birds - number of birds using any enrichment + number of birds under the platform or ramp) was calculated. As was the case for behavioral observations, some enrichment use (i.e., on the pecking stone, pecking the pecking stone, pecking the rope) occurred infrequently ( $<5 \%$ of all scans) and was not analyzed statistically.

A total of 3,167 scans, amounting to $1,467,1,249$, and 451 scans from d 26, 42, and 56, respectively, were performed. On each observation day, each pen was observed for 5 to 11 scans. Analysis included data from 163 pens. Each strain was represented in 8 to 12 pens. Across all trials the number of sampled pens for each category were as follows: CONV: 17 (d26/TW1), 9 (d42/TW2); FAST: 23 (d26), 24 (d42/TW1), 12 (d56/TW2); MOD: 25 (d26), 26 (d42/TW1), 14 (d56/TW2); SLOW: 28 (d26), 28 (d42/TW1), 15 (d56/TW2).

\section{Statistical Analysis}

To facilitate statistical analyses, the 14 strains were categorized into 4 groups according to ADG to TW 2 (described below), as follows: conventional (CONV; strains $\mathrm{B}$ and $\mathrm{C} ; \mathrm{ADG}_{0-47}=66.0-68.7 \mathrm{~g} /$ day $)$, fastest slow (FAST; strains F, G, I, M; $\mathrm{ADG}_{0-61}=53.5-55.5 \mathrm{~g} /$ day), moderate slow (MOD; strains $\mathrm{E}, \mathrm{H}, \mathrm{O}, \mathrm{S} ; \mathrm{ADG}_{0-}$ ${ }_{61}=50.2-51.2 \mathrm{~g} /$ day $)$, and slowest slow (SLOW; strains $\mathrm{D}, \mathrm{J}, \mathrm{K}, \mathrm{N} ; \mathrm{ADG}_{0-61}=43.6-47.7 \mathrm{~g} /$ day). Results from each of the three sets of data (i.e., inactivity, behavioral time budgets and frequencies, and enrichment use) were compared between categories, to assess differences at different growth rates, and between strains within categories, to assess differences at similar growth rates. Comparisons were made at the same age and at the same target weight, and models to evaluate the effects of age and body weight on each outcome were run separately.

Inactivity was analyzed using generalized linear mixed models in SAS 9.4, with pen as the experimental unit, and block and block nested within trial as random effects. CONV birds were only raised until wk 7 , producing holes in the data for wk 8 and 9; this necessitated running two models to evaluate the effect of age across categories: wk 4 to 7, for all categories; and wk 8 and 9, for slower growing categories only. Four additional age models (1 model per category) were built to compare differences within the same category over time, to assess when inactivity ceased to continue to increase; again, this was necessary due to the holes in the data. All age models used daily inactivity counts and week of age as a repeated measure, with a compound symmetry covariance structure, as it produced the lowest Aikaike information criterion value. The TW model used the mean daily inactivity count from the $7 \mathrm{~d}$ prior to processing. For all inactivity models, fixed effects were category, strain nested within category, and bird sex; TW or week of age was also included as a fixed effect, depending on the model in question. Interactions included in both the age and weight models were sex $\times$ category and sex $\times$ strain (category). The age models also included age $\times$ category and age $\times$ strain (category), whereas the weight model also included TW $\times$ category and TW $\times$ strain (category).

Behavior and enrichment use were analyzed using generalized linear mixed models in SAS 9.4, with pen as the experimental unit, and block and block nested within trial as random effects. Again, since CONV birds were raised until d 48 , there were holes in the data for the observations performed on d 56. As such, 2 models were built to evaluate the effect of age: $\mathrm{d} 26$ and 42 , for all categories, with age as a repeated measure and using the covariance structure that produced the lowest Akaike information criterion value; and $\mathrm{d}$ 
56 , for slower growing categories only. For all behavioral observation models, the fixed effects were identical to those listed for the inactivity models, except for the addition of observer as a fixed effect. The fixed effects were also similar in the enrichment use models, with the addition of observer and the removal of bird sex and its interactions, since observations were conducted on a pen basis, with pens including both male and female birds.

For all models, linearity and the homogeneity of effects were assessed using scatterplots and boxplots of studentized residuals. Normality was assessed using quantilequantile plots and Shapiro-Wilk tests. Selection of the most appropriate distribution was based on residual analysis; thus, the selected distribution varied depending on the model so as to meet model assumptions. The Kenward Roger method was used to compute denominator degrees of freedom. $P$-values were adjusted for multiple comparisons using the Tukey adjustment. Significance was set at an adjusted $P$-value $<0.05$. To facilitate the interpretation of inactivity results, back-transformed least-square mean inactivity counts were converted into minutes, wherein 1 inactivity count equals $15 \mathrm{~s}$ of inactivity.

\section{RESULTS}

\section{Inactivity Measurement}

By Age Inactivity increased as the birds aged. As shown in Figure 1, inactivity reached a maximum of $1,134 \mathrm{~min}$, or $78 \%$ of the day, at wk 7 for conventional strains and approximately $1,150 \mathrm{~min}$, or $80 \%$ of the day, at wk 9 for slower growing strains. Although all categories eventually reached similar levels of inactivity, the age at which inactivity ceased to increase differed by category. Week to week, CONV inactivity levels increased until wk 6 (all pairwise $P<0.01$ for wk 4-6), after which point inactivity did not differ (wk 6 vs. $7: P=0.84$ ).
Similarly, FAST inactivity increased until wk 8 (all pairwise $P<0.0001$ for wk 4-8), MOD inactivity increased until wk 6 (all pairwise $P<0.01$ for wk 4-6), and SLOW inactivity increased until wk 8 (all pairwise $P<$ 0.0001 for wk 4-8).

Differences between categories were greatest at younger ages (Figure 1). At wk 4, CONV were more inactive than MOD $(P<0.0001)$ and SLOW $(P<0.0001)$, equating to differences of 113 and $115 \mathrm{~min}$ per day, respectively. At wk 4, FAST were more inactive than MOD $(P=0.0068)$ and SLOW $(P=0.0054)$, with differences of 63 and 66 min per day, respectively. At wk 5 , CONV were more inactive than SLOW $(\mathrm{P}=0.0410)$; CONV were inactive for $1,072 \pm 23$ min per day, whereas SLOW were inactive for $999 \pm 14$ min per day, or 73 min per day less than CONV. Starting from wk 6, all categories had similar levels of inactivity.

Within categories, MOD strains had different levels of inactivity, but only at younger ages. At wk 4, one strain $(\mathrm{H})$ had lower daily inactivity levels than the 3 other MOD strains (E, O, and S; all pairwise $P<0.0001$ ); $\mathrm{H}$ was inactive for $710 \pm 21$ min per day, whereas the mean inactivity level of $\mathrm{E}$, $\mathrm{O}$, and $\mathrm{S}$ was 1,007 min per day, equating to a difference of $296 \mathrm{~min}$. At wk $5, \mathrm{H}$ tended to be less inactive than $\mathrm{E}$ and $\mathrm{S}(P=0.0962$ and 0.0602 , respectively); $\mathrm{H}$ was inactive for $128 \mathrm{~min}$ less than the mean daily inactivity level of $\mathrm{E}$ and $\mathrm{S}$. At all other ages, MOD strains did not differ. Conversely, within each category and at the same age, CONV, FAST, and SLOW strains had similar levels of inactivity; this was true for all ages.

Overall, females were more inactive than males; this amounted to a difference of $203 \mathrm{~min}$ per day during wk 4 to 7 , and 139 min per day during wk 8 to $9(P<0.0001$ for both). There were significant interactions between sex and category, as well as between sex and strain nested within category (see Supplementary Material and Supplementary Tables 2-3).

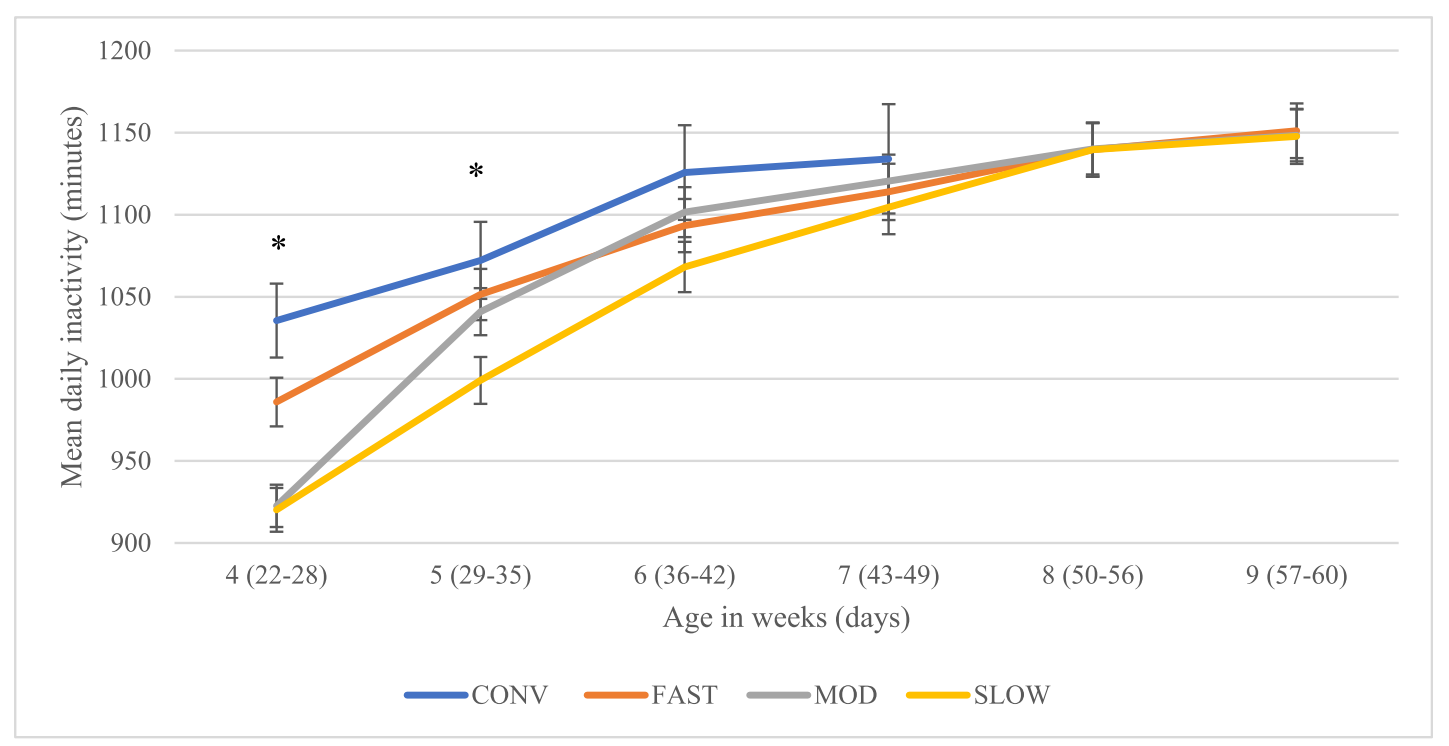

Figure 1. Mean daily inactivity levels by category at the same age, as measured using an omni-directional accelerometer (back-transformed LSmeans $\pm \mathrm{SEM}) .{ }^{*}$ At the same age, categories differ at adjusted $P<0.05$. 


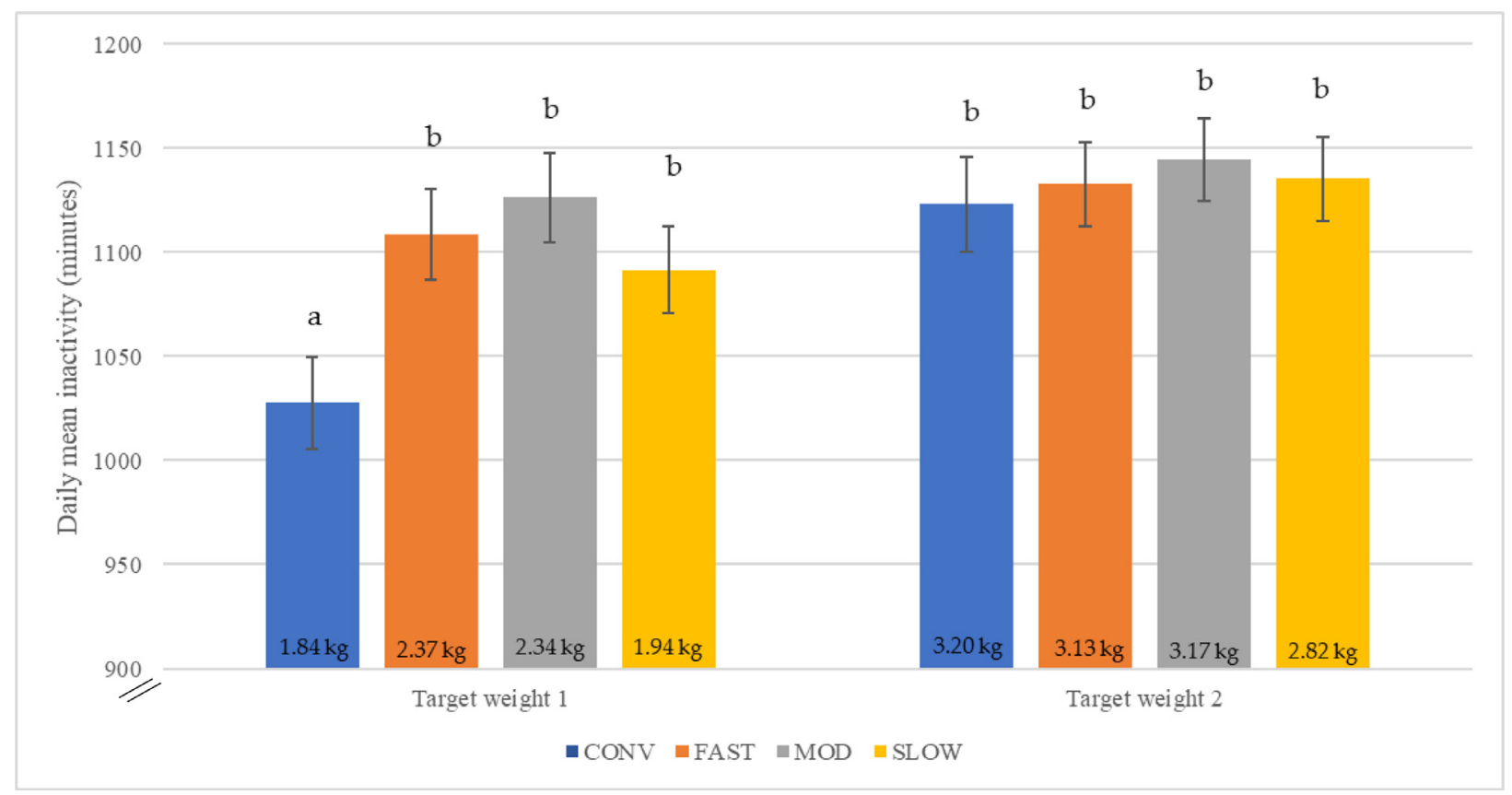

Figure 2. Mean daily inactivity levels by category at similar target weights (back-transformed LS-means \pm SEM). At target weight 1 , CONV were $26 \mathrm{~d}$ of age, whereas the other strains were $42 \mathrm{~d}$ of age. At target weight 2 , CONV were $42 \mathrm{~d}$ of age whereas the other strains were $56 \mathrm{~d}$ of age. Mean body weight $(\mathrm{kg})$ within category is displayed within the bars. Bars with no common superscript differ at adjusted $P<0.05$.

By Target Weight Inactivity tended to increase as body weight increased $\left(\mathrm{F}_{1,14}=3.16, P=0.0977\right)$. CONV birds were inactive for 96 more minutes at TW 2 than at TW $1(P=0.0447)$. For FAST, MOD, and SLOW birds compared across TW, activity levels at TW1 did not differ from those at TW2 (all $P>0.05$ ).

Differences between categories only existed at the lighter TW (Figure 2). At TW 1, CONV had a mean daily inactivity level of $1028 \pm 22 \mathrm{~min}$ and were less inactive than FAST $(P=0.0002)$, MOD $(P<0.0001)$, and SLOW $(P=0.0021)$; these differences corresponded to 79,98 , and $64 \mathrm{~min}$, respectively. At TW 2, all categories had similar mean daily levels of inactivity, ranging from 1,124 to 1,145 min per day, or 78 to $79 \%$ of the day. Within categories, at the same weight, strains had similar levels of inactivity.

Inactivity levels were affected by the birds' sex, with females again being more inactive than males $(P<$ 0.0001). Females were inactive for $1,127 \pm 14$ min per day, whereas males were inactive for $1,094 \pm 14$ min per day, or 33 min less than females. The effect of sex on inactivity did not depend on $\mathrm{TW}\left(\mathrm{F}_{1,187}=0.20\right.$, $P=0.66)$, category $\left(\mathrm{F}_{3,187}=0.23, P=0.87\right)$, or strain nested within category $\left(\mathrm{F}_{10,187}=0.28, P=0.98\right)$.

\section{Behavioral Observations}

Some behaviors occurred too infrequently to analyze statistically. Foraging and dustbathing occurred in 4 and $2 \%$ of all observations, respectively, making the mean proportion of time spent foraging and dustbathing only 0.29 and $0.74 \%$ overall; when they did occur, they amounted to 8.26 and $35.5 \%$ of the observation. In terms of the event behaviors that occurred too infrequently to analyze, the following mean number of events were observed per 5-min observation period: wing flapping: 0.09; jumping: 0.04; feather ruffling: 0.10; head scratching: 0.42 ; pecking at rope: 0.11 ; and pecking at backpack: 0.01 .

By Age The time spent performing many behaviors was affected by category, but these differences only occurred at younger ages (Figure 3). At d 26, CONV spent more time sitting (Figure $3 \mathrm{~A}$ ) and less time standing (Figure 3B) and walking (Figure 3C) than FAST, MOD, and SLOW, but birds in all 4 categories spent similar amounts of time feeding (Figure 3D), drinking and preening. At d 42, CONV spent less time sitting than FAST, less time standing than MOD and SLOW, less time walking than SLOW, and more time feeding than FAST, MOD, and SLOW. There were also differences between the slower growing categories at d 42, with FAST sitting more and walking less than SLOW. Nonetheless, at d 42, there were no differences between the length of time any category spent drinking or preening. Additionally, at d 56, there were no differences between categories in the duration of any behaviors. At all ages, in terms of differences between categories, "all sitting" was similar to sitting, "all standing" was similar to standing, and locomotion was similar to walking; in other words, accounting for the time spent sidelying, performing other behaviors while sitting or standing, or running did not change the results. When behaviors were compiled to reflect the total time spent off feet, differences between categories only emerged at d 26, with CONV spending more time off feet than MOD and SLOW (Figure 3E).

Bout frequencies were also affected by category, although to a lesser extent than durations (Table 2). At d 26, CONV performed fewer bouts of standing and 


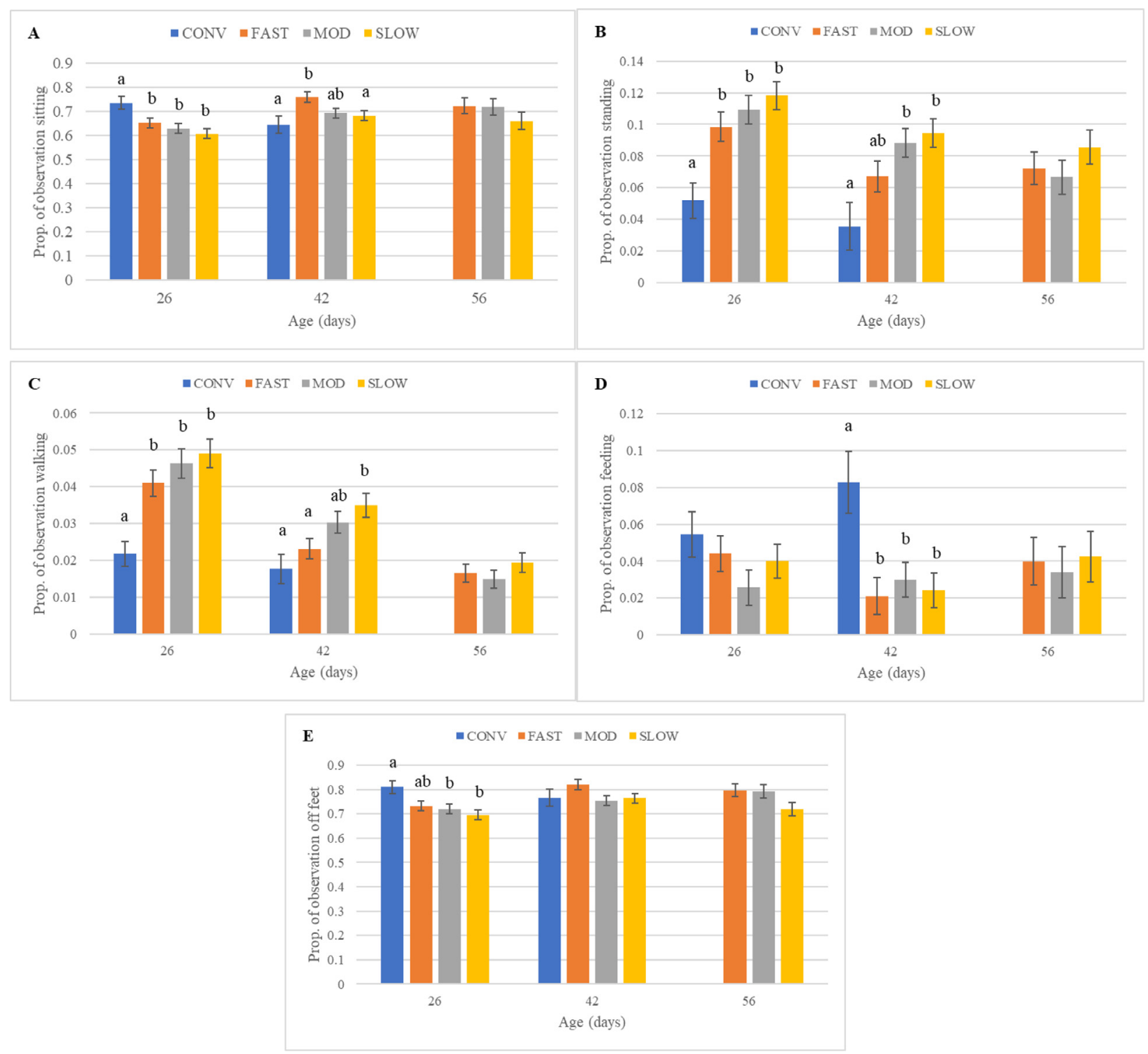

Figure 3. Proportion of time birds spent (A) sitting; (B) standing; (C) walking; (D) feeding; and (E) off feet, assessed over a 300-s observation period, by category at the same age (back-transformed LS-means \pm SEM). Bars with no common superscript differ at adjusted $P<0.05$.

walking than all 3 slower growing categories (i.e., FAST, MOD, and SLOW); in other words, it appears that CONV performed these behaviors less frequently overall, in addition to spending less time performing them (see above). Additionally, CONV engaged in fewer preening bouts than MOD and fewer leg stretches than FAST and MOD broilers. Similarly, at d 42, CONV also performed fewer bouts of standing and walking than MOD and SLOW, with FAST also performing fewer walking bouts than SLOW. There were no category differences in the number of bouts of any other behaviors at $\mathrm{d} 26$ and 42, and no differences in any behaviors at d 56.

Within categories, strains generally behaved similarly, with a few exceptions. There were no differences between strains within CONV and MOD for both the total duration and number of bouts of all behaviors. Within FAST, there was one difference between strains: strain M stood for longer than strain F $(13.76 \pm 1.97 \%$ vs. $5.61 \pm 1.49 \%, P=0.0414)$, but only on $d 26$; these and all other FAST strains did not differ in their time budgets at any other ages (see Supplementary Table 4). Similarly, within SLOW, there were 2 differences between strains, and only at d 26: strain D spent a longer proportion of the observation walking than strain $\mathrm{K}$ $(7.40 \pm 0.90 \%$ vs. $3.43 \pm 0.60 \%, P=0.0231$; see Supplementary Table 5) and strain J performed more sitting bouts than strain $\mathrm{N}(1.48 \pm 0.11$ vs. $1.02 \pm 0.11$, $P=0.0332$ ); SLOW strains did not differ in their time budgets or bout frequencies at any other ages.

Behavior was also affected by sex, but only for preening and feeding, with some interactions with category. In brief, at some ages and for some categories, females preened more and fed less than males (see Supplementary Material).

Finally, with respect to the time broilers spent on the litter, there were no differences between categories, with time ranging from $77.39 \%$ for MOD to $82.07 \%$ for CONV; however, there were differences between 2 strains within SLOW at d $26(\mathrm{~J}=87.65 \pm 5.27 \%$ vs. 


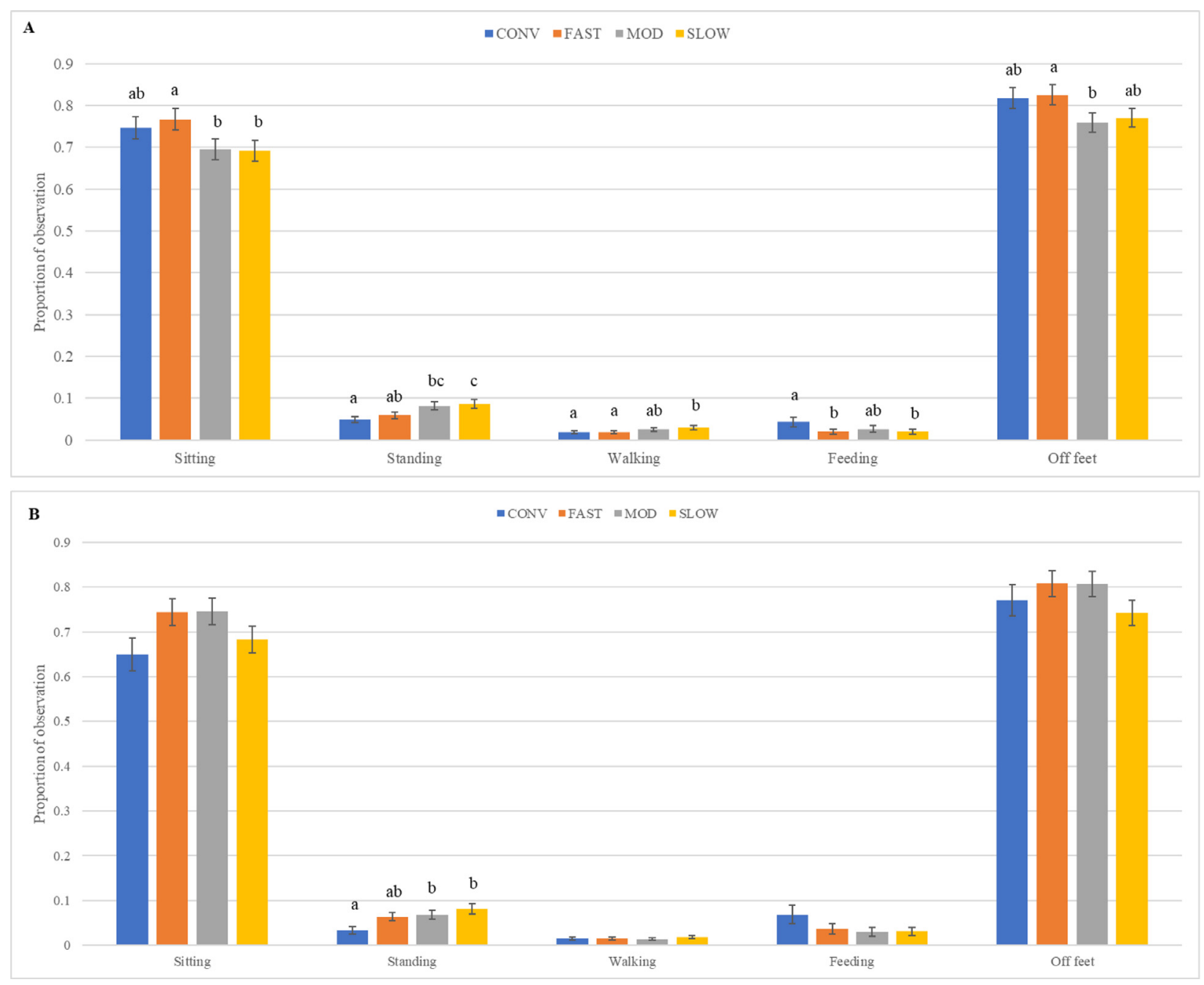

Figure 4. Proportion of time birds spent sitting, standing, walking, feeding, and off feet, assessed over a 300-s observation period, by category at a similar (A) lighter target weight (target weight 1) and (B) heavier target weight (target weight 2) (back-transformed LS-means \pm SEM). At target weight 1, CONV were $26 \mathrm{~d}$ of age, whereas the other strains were $42 \mathrm{~d}$ of age. At target weight 2 , CONV were $42 \mathrm{~d}$ of age whereas the other strains were $56 \mathrm{~d}$ of age. Bars with no common superscript differ at adjusted $P<0.05$.

$\mathrm{K}=62.10 \pm 5.46 \%, P=0.0385)$ and between 2 strains within FAST at $\mathrm{d} 42(\mathrm{~F}=97.30 \pm 5.04 \%$ vs. $\mathrm{G}=71.60$ $\pm 5.34 \%, P=0.0215)$.

By Target Weight At the same TW, broilers in different categories behaved differently. At TW 1, CONV spent less time standing than MOD and SLOW, less time walking than SLOW, and more time feeding than FAST and SLOW (Figure 4A). FAST spent more time sitting than MOD and SLOW, and less time standing and walking than SLOW. Categories did not differ in the time spent drinking or preening. When compiled into off-feet behaviors, FAST spent more time off feet than MOD. By TW 2, almost all the category differences noted at TW 1 had disappeared. More specifically, categories did not differ in the length of time spent sitting, walking, feeding, drinking, or preening, nor did they differ in the total time spent off (Figure 4B); however, CONV did spend less time standing than MOD and SLOW ( $P=0.0324$ and 0.0028 , respectively). As was noted for the age analysis, at both TW, differences between categories in "all sitting", "all standing", and locomotion matched the differences noted in sitting, standing, and walking, respectively.

As shown in Table 3, bout frequencies were also affected by category, but only for some behaviors. At TW 1, there were differences across categories in the number of bouts of standing and walking, with CONV having fewer standing bouts than MOD and SLOW (both $P<0.05$ ), and FAST having fewer walking bouts than SLOW $(P=0.0053)$. At TW 2 , categories only differed in the number of preening bouts, with FAST performing fewer preening bouts than SLOW $(P=0.0463)$. Otherwise, at both TW, there were no category differences in the bout frequencies of all other behaviors.

Similar to the pattern revealed through age analysis, at similar body weights, the strains within each category behaved similarly; there were no differences between strains within each of the four categories in terms of both the total duration and number of bouts for all analyzed behaviors (all $P>0.05$ ).

Lastly, at the same TW, there were no differences in the total duration each category spent on the litter, with 
values ranging from $80.71 \pm 3.16 \%$ for CONV to $82.41 \pm$ $2.97 \%$ for FAST.

\section{Enrichment Use}

By Age The use of most enrichment objects was generally dependent on the category (Figure 5). At all ages, the proportion of birds using any of the available enrichments differed across categories (Figure 5A), with a lower proportion of CONV using all enrichments than all slower growing categories. There were also differences amongst slower growing categories: a higher proportion of SLOW than FAST and MOD birds used all enrichments on d 26 and 56. MOD enrichment use was also greater than FAST at d 56. A similar pattern was evident for the proportion of birds on the platform, with CONV always on the platform in a smaller proportion than all slower growing categories, and some differences between slower growing categories at d 26 and 56 (Figure 5B). Conversely, at all 3 ages, there were no differences in the proportion of birds using the area under the platform and ramp. Use of the hanging scale did not follow a consistent pattern in line with ADG (Figure 5C). MOD used the scale more than SLOW at $d$ 26, and more than CONV at d 42. FAST used it less than MOD and SLOW at d 56. On the other hand, the proportion of birds on the litter generally decreased with decreasing ADG (Figure 5D), with all four categories using the litter differently on d 26, CONV differing from all slower-growing categories on d 42, and all 3 slower growing categories differing from each other on d 56 .
Within categories, all CONV strains demonstrated a similar use of enrichments and the litter. Conversely, some strains within FAST, MOD, and SLOW used enrichments differently. Within the FAST and MOD categories (Supplementary Tables 6-7), enrichment use by one strain ( $\mathrm{F}$ and $\mathrm{E}$, respectively) was often different from some or all other strains within the category; however, within the SLOW category, there was no consistent pattern in the strains that differed from each other (Supplementary Table 8).

By Target Weight At the same target body weight, enrichment use generally differed across categories, but not for every enrichment (Figure 6). At TW 1, a larger proportion of SLOW than CONV, FAST, and MOD were observed using all enrichments, on top of the platform, and using the area under the platform and ramp; however, there were no differences in the proportion of birds using the scale (Figure 6A). There were also few differences in the proportion of birds on the litter, with only FAST present on the litter in a greater proportion than SLOW $(84.64 \pm 0.56 \%$ vs. $83.46 \pm 0.57 \%$, $P=0.0012$ ). At TW 2, the proportion of birds engaged in the use of enrichments generally increased as growth rate decreased (Figure 6B). CONV used all enrichments to a lesser extent than MOD and SLOW, whereas FAST and MOD each also used all enrichments less than SLOW. When each enrichment item was considered separately, there were fewer differences between categories: use of the top of the platform followed a similar pattern as all enrichment use, but with no difference between MOD and SLOW $(P=0.29)$, whereas there no differences in use of the area under the platform and ramp, and
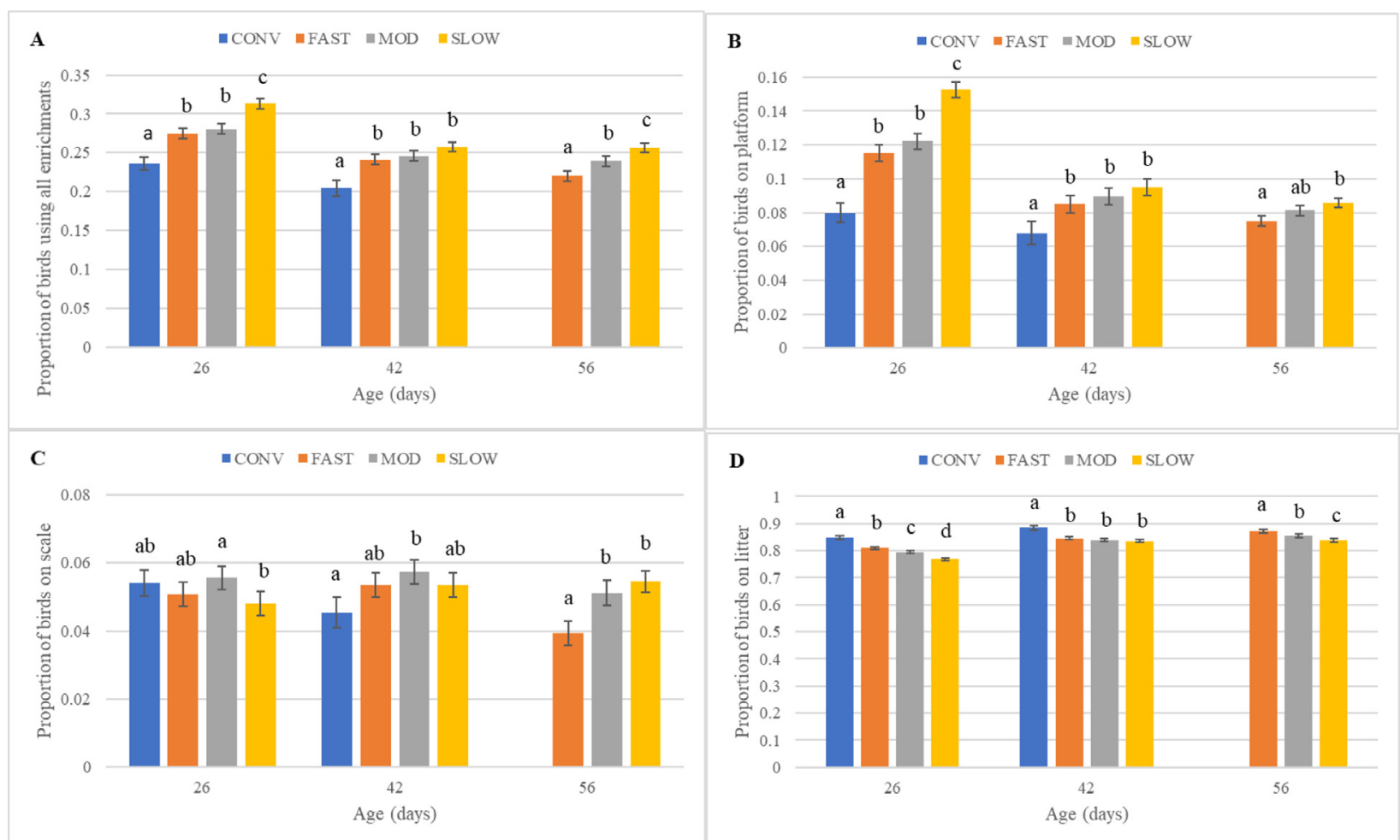

Figure 5. Enrichment use by category at the same age, assessed as the proportion of birds in the pen: (A) using all enrichments; (B) on the platform; (C) on the scale; and (D) on the litter (back-transformed LS-means \pm SEM). Bars with no common superscript differ at adjusted $P<0.05$. 


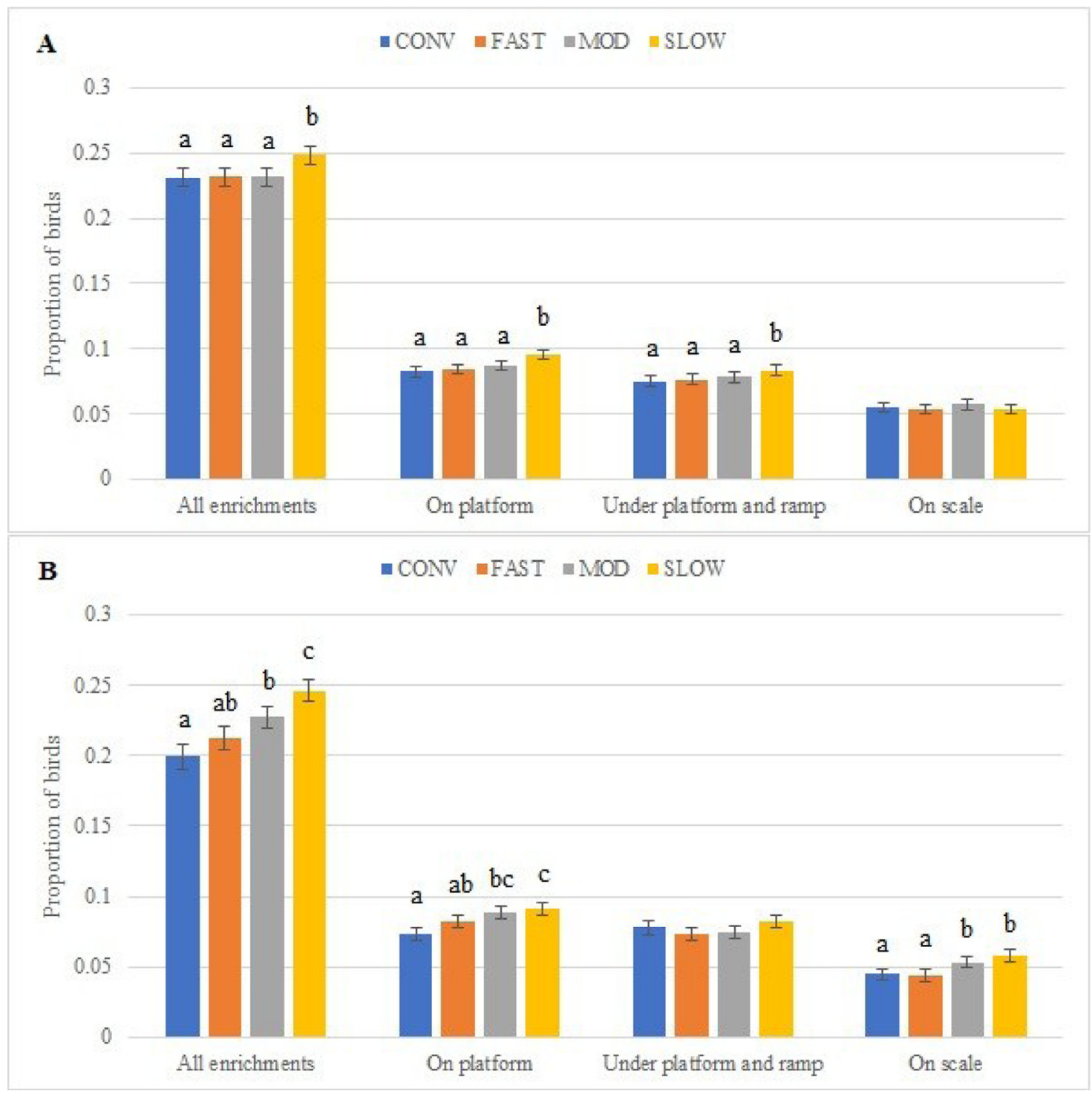

Figure 6. Enrichment use by category, assessed as the proportion of birds in the pen using various enrichment items and on the litter at a similar (A) lighter target weight (target weight 1) and (B) heavier target weight (target weight 2) (back-transformed LS-means \pm SEM). At target weight 1, CONV were $26 \mathrm{~d}$ of age, whereas the other strains were $42 \mathrm{~d}$ of age. At target weight 2 , CONV were $42 \mathrm{~d}$ of age whereas the other strains were $56 \mathrm{~d}$ of age. Bars with no common superscript differ at adjusted $P<0.05$.

there were only differences in the use of the scale between the 2 faster (CONV, FAST) and 2 slower (MOD, SLOW) categories. Conversely, the proportion of birds on the litter decreased with growth rate, with a larger proportion of CONV on the litter $(88.39 \pm 0.78 \%)$ than all slower growing categories $(84.53 \pm 0.49 \%, 83.84$ $\pm 0.47 \%$, and $83.59 \pm 0.47 \%$ for FAST, MOD, and SLOW, respectively; all $P<0.03$ ) and a greater proportion of FAST and MOD on the litter than SLOW (all $P<0.01)$.

Within categories, there were some differences in the number of birds that engaged in enrichment use. Among CONV, these differences only appeared at TW 1 and only in the proportion of birds on the platform (Supplementary Table 9). Within FAST, although each strain at some point demonstrated different enrichment use than the others, 2 strains were often different than the other FAST strains: F and I (Supplementary Table 10). Within MOD, strains $\mathrm{E}$ and $\mathrm{O}$ were the only strains to differ from each other, and only in their use of all enrichments and the scale (Supplementary Table 11). Lastly, within SLOW, enrichment use by each of the 4 strains was at some point different from the others, with no consistent pattern across enrichments (Supplementary Table 12).

\section{DISCUSSION}

The aim of this study was to compare the behavior of conventional and slower growing broiler strains, at both the same age and similar body weights, by investigating inactivity levels, behavior durations and frequencies, and enrichment use. All strains were inactive for most of the day, eventually reaching similar inactivity levels; however, those with slower growth rates reached these levels at older ages. At the same age, faster growing strains had higher inactivity, but only at young ages. 
Behavioral time budgets were also affected by growth rate, with slower growing strains sitting and feeding less, and standing and walking more than fast-growing strains; these differences were more widespread at younger ages and/or the lighter TW. Enrichment use was higher in slower growing strains. When compared at the same ages, the proportion of birds using enrichments was higher when their growth rates were lower, whereas the proportion of birds on the litter was higher when their growth rates were also higher. At both TW, slower growing strains engaged in more enrichment use; however, there were more differences between categories at the heavier body weight.

Surprisingly, at TW $1(\sim 2.1 \mathrm{~kg})$, CONV were less inactive than all 3 slower growing categories, and spent a similar proportion of time sitting, as well as engaging in behaviors performed both off their feet. Additionally, at TW 1, CONV did not differ from FAST and MOD in enrichment use. CONV were 2 wk younger than the other categories at TW 1 (34 vs. $48 \mathrm{~d}$ of age). However, CONV birds were also lighter than the expected TW of $2.1 \mathrm{~kg}(\sim 1.8 \mathrm{~kg}$ at $\mathrm{d} 34)$ and lighter than FAST and MOD $(\sim 2.3 \mathrm{~kg})$ birds at d 48 (although similar to SLOW birds, $1.9 \mathrm{~kg}$, at d48; Torrey et al., 2021). This lighter weight may have been a consequence of consuming feed formulated for slower growing strains or being processed 2 and $3 \mathrm{~d}$ prior to the breeders' projections for reaching $2.1 \mathrm{~kg}$; given the magnitude of the project, both adjustments were necessary for logistical reasons. At TW $2(\sim 3.2 \mathrm{~kg})$, CONV had a similar BW to FAST and MOD, but were heavier than SLOW (Torrey et al., 2021), suggesting that these mismatches in anticipated body weight was mainly an issue at the lower TW. Nevertheless, given these weight differences, discussion of inactivity and behavior will focus on results from the age analyses. Conversely, discussion of enrichment use will include TW comparisons due the intrinsic limitation of body size on the number of birds that could use each enrichment item.

As expected, all broiler strains eventually reached high levels of inactivity, equivalent to approximately 78 to $80 \%$ of the day, despite being provided with enrichment objects that may increase activity. Other research, based on behavioral observations, has shown that conventional birds spend 70 to $86 \%$ of their time performing inactive behaviors (e.g., Weeks et al., 2000; Bokkers and Koene, 2003; Alvino et al., 2009; Bailie et al., 2013; Dixon, 2020). Few studies have raised slower growing broilers to 62 days of age; however, one study noted that older slower growing broilers ( $>7$ wk of age) spent $68 \%$ of observations sitting and lying (Bokkers and Koene, 2003). In contrast to previous research, our study continuously monitored activity, including overnight when broilers are known to be less active (Norring et al., 2016). As such, higher inactivity levels were expected compared to values from previous research; this expectation was also anticipated because sitting peaked at approximately 68 to $76 \%$ of observations, revealing that accelerometers capture more inactivity than day-time behavioral observations alone. On the other hand, the current results are likely conservative estimates of inactivity due to the accelerometer's sensitivity to small movements and the methodology applied to define each inactivity count (i.e., 15 consecutive seconds of 0 acceleration). This likely excluded bouts of low intensity, nonlocomotor behaviors, such as preening, which has been shown to lead to non-zero accelerometer counts in laying hens (Casey-Trott and Widowski, 2018). It may have also excluded periods of rest during which a bird wearing an Actical pecked at the litter, was bumped or pecked at by pen mates, or shifted between resting postures (e.g., transitioning from sitting to sidelying).

Observational behavioral data identified differences in the performance of specific behaviors, thus providing information to supplement general inactivity results. For some behaviors, the time budgets noted in this study were similar to those noted in other studies of conventional and slower growing broilers. For instance, across all strains and ages, the broilers in this study sat, stood, walked, and preened for about 607 to $5 \%, 3$ to $12 \%, 1$ to $5 \%, 5$ to $10 \%$ of observations, whereas Bokkers and Koene (2003) and Dixon (2020) noted that sitting, standing, locomotion, and preening accounted for approximately 45 to $70 \%, 4$ to $15 \%, 1$ to $14 \%$, and 4 to $12 \%$ of observations in similar-aged broilers. On the other hand, dustbathing and foraging were observed so infrequently that they could not be formally analyzed; they accounted for 0.74 and $0.29 \%$ of observations, compared to previous findings of 0 to $7 \%$ and 8 to $13 \%$, respectively (Bokkers and Koene, 2003; Dixon, 2020). Dustbathing is known to be affected by time of day, occurring more frequently in the afternoon (De Jong and Gunnink, 2019); therefore, the comparatively low occurrence in this study may be due to the timing of our behavioral observations (morning to early afternoon). In terms of foraging, the definition used by Dixon (2020) included "scratching or digging. . .with the beak or feet", whereas our definition required ground scratching with both legs in addition to ground pecking; our definition was thus more specific, and may have excluded instances that others may have considered to be foraging.

At the same age, platform use generally mimicked all enrichment use, suggesting that platforms were the most used enrichment; this may have been driven by a preference for elevated platforms over other types of enrichments, or by virtue of the platforms being large enough to simultaneously accommodate more birds than any other enrichment. At TW 2, when categories generally had similar body weights (Torrey et al., 2021), enrichment use followed growth rate, with faster-growing categories using enrichments less than slower growing categories; this suggests that physical ability rather than body size itself limited platform use, particularly since access necessitated mobility: walking up an inclined ramp. Similarly, Rayner et al. (2020) noted that faster growing broiler strains were observed on top of rectangular straw bales less frequently than slower growing strains. Since domestic fowl generally prefer to rest and roost in elevated locations, enrichment use has been suggested to be an indicator of positive welfare (e.g., 
Rayner et al., 2020). Conversely, oral enrichment items (i.e., the rope and stone) were used infrequently, in line with previous research demonstrating that platforms are used more often than oral enrichments (e.g., Bach et al., 2019). Altogether, our data reflects enrichment use during a portion of daylight hours, but it may be different if assessed at other times of day and/or over more scans.

Generally, behavioral data corroborated inactivity data. More specifically, the inactivity levels of CONV and MOD birds increased until wk 6 , whereas those of FAST and SLOW birds increased until wk 8. Similarly, as the birds aged, the proportion of time spent off feet (numerically) increased, whereas the proportion of time spent on feet decreased. These increases in inactivity and off-feet behaviors, like sitting, as well as decreases in on-feet behaviors, like standing and walking, may be due to an increased body weight or increasingly poor leg health, whereas category differences in the timing of these increases may have arisen due to their differences in growth rates. As broilers grow, their resting metabolic rate accounts for an increasing proportion of energy consumption, leaving less energy available for locomotor activity (Tickle et al., 2018), which likely, at least partially, contributed to increasing inactivity and off-feet behavior. Although this study did not assess either inactivity or behavior during the first 3 wk of life, Bizeray et al. (2000) noted that conventional and slower growing strains did not display differences in lying, standing, or walking behavior until d 15 , suggesting that it is unlikely that categories differed for long before the birds were outfitted with the accelerometers.

For the most part, at the same age, strains with similar growth rates behaved similarly. Within the CONV category, all strains demonstrated similar inactivity, behavioral time budgets, and enrichment use. Conversely, although only in a limited number of situations, some of the strains within all 3 slower growing categories differed from each other. Within all three categories, strains with similar growth rates sometimes engaged in different enrichment use; however, there was no consistent pattern with respect to specific outlier strains or specific enrichment types. Within the FAST category, 2 strains differed from each other in their standing durations, but only at the youngest age, and not for any other behaviors. Within the MOD category, one strain $(\mathrm{H})$ had lower inactivity levels, but only at a young age; investigation of the interaction between sex and strain nested within category revealed that this difference was likely driven by the male birds. Lastly, 2 SLOW strains differed in walking duration, whereas the other 2 SLOW strains performed a different number of sitting bouts; thus, all 4 demonstrated differences at some point. Mancinelli et al. (2020) noted that some organically reared slower growing strains demonstrated different degrees of static behavior, despite having similar growth rates. This suggests that aspects other than overall growth rate may impact behavior, such as temperament, strain-specific growth curves, or differences in conformation or body proportions (e.g., muscle distribution). For instance, strain $\mathrm{H}$ had a lower ADG than other MOD strains from approximately 17 to 35 d (Torrey et al., 2021), which corresponded to the time period when strain $\mathrm{H}$ inactivity differed from that of other MOD strains. Future analyses using other data collected as part of this large-scale study will examine whether outlier strains differ in other characteristics that may explain the limited within-category behavior differences.

Although there were few differences between strains with similar growth rates (within categories), inactivity, and behavior were not similar across all slower growing strains. Among the 12 slower growing strains included in this study, ADG to the higher TW had a wide range, from 43.6 to $55.5 \mathrm{~g}$ /day (Torrey et al., 2021). At the same age, FAST birds $\left(\mathrm{ADG}_{0-61}=53.5-55.5 \mathrm{~g} / \mathrm{day}\right)$ were as inactive as $\mathrm{CONV}$ birds $\left(\mathrm{ADG}_{0-47}=66.0-68.7\right.$ $\mathrm{g} /$ day); this was the case at all ages. FAST birds were more inactive than $\mathrm{MOD}\left(\mathrm{ADG}_{0-61}=50.2-51.2 \mathrm{~g} /\right.$ day $)$ and SLOW $\left(\mathrm{ADG}_{0-61}=43.6-47.7 \mathrm{~g} /\right.$ day $)$ birds, although only at young ages. At 42 days of age, FAST also stood and walked as little as CONV, both in duration and number of bouts, and spent similar amounts of time both off their feet, while also sitting more and walking less than SLOW.

Changes in behavior, particularly active behaviors such as standing or walking, may be the result of a lack of physical ability or a lack of motivation to be active or perform certain behaviors; distinguishing between these 2 potential causes is important for interpreting behavior changes with respect to welfare. Different strains may have different temperaments or body conformation, which could affect their overall behavior. Since conventional strains have been selected for high feed efficiency, it is possible that they have been indirectly selected for low locomotor activity (Bizeray et al., 2000). As such, the behavior differences demonstrated in this study could be due to differences in the inherent characteristics of the tested strains. If this is the case, then there is less cause for concern with respect to welfare. On the other hand, Bokkers and Koene (2004) found that walking for a food reward is limited by motivation in slow-growing birds and physical ability in fast-growing birds. Their results suggest that immobility rather than motivation may be responsible for more inactivity and sitting, and less standing and walking among conventional broiler strains, or broilers with heavier body weights due to either their strain or age; this may impair broiler welfare through the inability to perform behaviors that they are motivated to perform.

Although the focal birds were randomly selected from the sentinel birds (whose body weight matched the mean strain body weight at hatch), individual variation in growth rates may have led to the focal birds not being entirely representative of all birds in the pen in terms of their body weights, with consequences on their behavior. As such, this may have introduced variability into the data.

This study suggests that inactivity, behavior, and enrichment use differ with broilers' growth rates, with faster growing strains demonstrating more inactivity, more sitting and feeding, less standing and walking, and 
lower rates of enrichment use. Future analyses will investigate if and how these behaviors correlate with other outcome measures of health and welfare, such as the performance of behaviors indicative of positive welfare (e.g., play behavior), mobility as assessed via latency-to-lie and obstacle tests, or health-related outcomes associated with different behaviors, particularly sitting and general inactivity, such as the incidence and severity of foot pad dermatitis or hock burn. Altogether, results suggest that not all slower-growing strains are equal, nor are they all different from conventional strains. As such, the use of any strain labeled as "slow growing", without considering its specific growth rate, may not necessarily lead to improved welfare, at least not in terms of decreased inactivity, the performance of a full behavioral repertoire, and an increased use of enrichments.

\section{ACKNOWLEDGMENTS}

We are grateful for the in-kind contributions from the Ontario Agri-Food Innovation Alliance, the anonymous breeding companies and Protekta, Inc. We are indebted to the Arkell Research Station staff for their assistance with ensuring the project's success. We thank all our student assistants for their aid with accelerometer installation and behavioral observations (in alphabetical order): Alan Abdulkadar, Madeleine Browne, Veronica Cheng, Melanie Felker, Narissa Leslie, Nyasha Mombeshora, Siobhan Mellors, Quinn Rausch, Megan Weckworth, and Leah Wellard. This research was funded by Global Animal Partnership (grant number 053143) and the Canada First Research Excellence Fund (grant number 499028/499064).

\section{DISCLOSURES}

All authors approved the manuscript prior to its submission to Poultry Science. The manuscript has not been published nor is it under consideration by any other journal. We have no conflicts of interest to declare.

\section{SUPPLEMENTARY MATERIALS}

Supplementary material associated with this article can be found in the online version at doi:10.1016/j. psj.2021.101451.

\section{REFERENCES}

Alvino, G. M., G. S. Archer, and J. A. Mench. 2009. Behavioural time budgets of broiler chickens reared in varying light intensities. Appl. Anim. Behav. Sci. 118:54-61.

Bach, M. H., F. M. Tahamtani, I. J. Pedersen, and A. B. Riber. 2019 Effects of environmental complexity on behaviour in fast-growing broiler chickens. Appl. Anim. Behav. Sci. 219:104840.

Bailie, C. L., M. E. E. Ball, and N. E. O'Connell. 2013. Influence of the provision of natural light and straw bales on activity levels and leg health in commercial broiler chickens. Animal 7:618-626
Bailie, C. L., and N. E. O'Connell. 2015. The influence of providing perches and string on activity levels, fearfulness and leg health in commercial broiler chickens. Animal 9:660-668.

Bassler, A. W., C. Arnould, A. Butterworth, L. Colin, I. C. De Jong, V. Ferrante, P. Ferrari, S. Haslam, F. Wemelsfelder, and H. J. Blokhuis. 2013. Potential risk factors associated with contact dermatitis, lameness, negative emotional state, and fear of humans in broiler chicken flocks. Poult. Sci. 92:2811-2826.

Bessi, W. 2006. Welfare of broilers: a review. Worlds Poult. Sci. J. 62:455-466.

Bizeray, D., I. Estevez, C. Leterrier, and J. M Faure. 2002. Effects of increasing envrionmental complexity on the physical activity of broiler chickens. Appl. Anim. Behav. Sci. 79:27-41.

Bizeray, D., C. Leterrier, P. Constantin, M. Picard, and J. M. Faure. 2000. Early locomotor behaviour in genetic stocks of chickens with different growth rates. Appl. Anim. Behav. Sci. $68: 231-242$

Bokkers, E. A. M., and P. Koene. 2003. Behaviour of fast- and slow growing broilers to 12 weeks of age and the physical consequences. Appl. Anim. Behav. Sci. 81:59-72.

Bokkers, E. A. M., and P. Koene. 2004. Motivation and ability to walk for a food reward in fast- and slow-growing broilers to 12 weeks of age. Behav. Processes 67:121-130.

Bokkers, E. A. M., P. H. Zimmerman, T. Bas Rodenburg, and P. Koene. 2007. Walking behaviour of heavy and light broilers in an operant runway test with varying durations of feed deprivation and feed access. Appl. Anim. Behav. Sci. 108:129-142.

Bradshaw, R. H., R. D. Kirkden, and D. M. Broom. 2002. A review of the aetiology and pathology of leg weakness in broilers in relation to their welfare. Avian Poult. Biol. Rev. 13:45-103.

Casey-Trott, T. M., and T. M. Widowski. 2018. Validation of an accelerometer to quantify inactivity in laying hens with or without keel-bone fractures. Anim. Welf. 27:103-114.

Cheema, M. A., M. A. Qureshi, and G. B. Havenstein. 2003. A comparison of the immune response of a 2001 commercial broiler with a 1957 randombred broiler strain when fed representative 1957 and 2001 broiler diets. Poult. Sci. 82:1519-1529.

Danbury, T. C., C. A. Weeks, J. P. Chambers, and S. C. Kestin. 2000. Self-selection of the analgesic drug carprofen by lame broiler chickens. Vet. Rec. 146:307-311.

Dawkins, M. S. 1989. Time budgets in red junglefowl as a baseline for the assessment of welfare in domestic fowl. Appl. Anim. Behav. Sci. 24:77-80.

De Jong, I. C., and H. Gunnink. 2019. Effects of a commercial broiler enrichment programme with or without natural light on behaviour and other welfare indicators. Animal 13:384-391.

De Jong, I. C., H. Gunnink, and J. Van Harn. 2014. Wet litter not only induces footpad dermatitis but also reduces overall welfare, technical performance, and carcass yield in broiler chickens. J. Appl. Poult. Res. 23:51-58.

de Godoy, M. R. C., and A. K. Shoveller. 2017. Overweight adult cats have significantly lower voluntary physical activity than adult lean cats. J. Feline Med. Surg. 19:1267-1273.

Dixon, L. M. 2020. Slow and steady wins the race: the behaviour and welfare of commercial faster growing broiler breeds compared to a commercial slower growing breed. PLoS One 15:1-21.

Fanatico, A. C., C. M. Owens, J. A. Mench, J. L. Emmert, P. B. Pillai, C. Falcone, and P. Y. Hester. 2008. Performance, livability, and carcass yield of slow- and fast-growing chicken genotypes fed low-nutrient or standard diets and raised indoors or with outdoor access. Poult. Sci. 87:1012-1021.

Fanatico, A. C., P. B. Pillai, L. C. Cavitt, C. M. Owens, and J. L. Emmert. 2005. Evaluation of slower-growing broiler genotypes grown with and without outdoor access: growth performance and carcass yield. Poult. Sci. 84:1321-1327.

Haslam, S. M., S. N. Brown, L. J. Wilkins, S. C. Kestin, P. D. Warriss, and C. J. Nicol. 2006. Preliminary study to examine the utility of using foot burn or hock burn to assess aspects of housing conditions for broiler chicken. Br. Poult. Sci. 47:13-18.

Havenstein, G. B., P. R. Ferket, and M. A. Qureshi. 2003a. Growth, livability, and feed conversion of 1957 versus 2001 broilers when fed representative 1957 and 2001 broiler diets. Poult. Sci. 82:1500-1508.

Havenstein, G. B., P. R. Ferket, and M. A. Qureshi. 2003b. Carcass composition and yield of 1957 versus 2001 broilers when fed representative 1957 and 2001 broiler diets. Poult. Sci. 82:1509-1518. 
Haye, U., and C. M. Simons. 1978. Twisted legs in broilers. Br. Poult. Sci. 19:549-557.

Kaukonen, E., M. Norring, and A. Valros. 2017. Perches and elevated platforms in commercial broiler farms: use and effect on walking ability, incidence of tibial dyschondroplasia and bone mineral content. Animal 11:864-871.

Kestin, S. C., S. Gordon, and G. Su. 2001. Relationships in broiler chickens between lameness, liveweight, growth rate and age. Vet. Rec. 148:195-198.

Kuttappan, V. A., B. M. Hargis, and C. M. Owens. 2016. White striping and woody breast myopathies in the modern poultry industry: a review. Poult. Sci. 95:2724-2733.

Lascelles, B. D. X., B. D. Hansen, A. Thomson, C. C. Pierce, E. Boland, and E. S. Smith. 2008. Evaluation of a digitally integrated accelerometer-based activity monitor for the measurement of activity in cats. Vet. Anaesth. Analg. 35:173-183.

Lichovníková, M., D. Hampel, Š. Nedomová, L. Kupčíková, and V. Anderle. 2017. The effect of genotype on the behaviour of free range chickens. J. Cent. Eur. Agric. 18:632-645.

Liu, Z. 2019. The effects of environmental enrichment on the health, behaviour, and welfare of fast-growing broilers. MSc Thesis. Univ. Guelph, Canada.

Mancinelli, A. C., S. Mattioli, A. D. Bosco, A. Aliberti, M. G. Amato, and C. Castellini. 2020. Performance, behavior, and welfare status of six different organically reared poultry genotypes. Animals 10:550.

McGeown, D., T. C. Danbury, A. E. Waterman-Pearson, and S. C. Kestin. 1999. Effect of carprofen on lameness in broiler chickens. Vet. Rec. 144:668-671.

McHugh, M. L. 2012. Interrater reliability: the kappa statistic. Biochem. Medica 22:276-282.

Norring, M., E. Kaukonen, and A. Valros. 2016. The use of perches and platforms by broiler chickens. Appl. Anim. Behav. Sci. 184:91-96.

Rayner, A. C., R. C. Newberry, J. Vas, and S. Mullan. 2020. Slow-growing broilers are healthier and express more behavioural indicators of positive welfare. Sci. Rep. 1-14.

Reiter, K., and W. Bessei. 1998. Effect of locomotor activity on bone development and leg disorders in broilers. Arch. Geflugelkunde 62:247-253.

Reiter, K., and W. Bessei. 2011. Effect of reduced weight load on locomotor activity and leg disorders in broiler chicken. Pages 113-118 in Proceedings of the 6th European Symposium on Poultry Welfare.

Rialland, P., C. Otis, M. L. de Courval, P. Y. Mulon, D. Harvey, S. Bichot, D. Gauvin, A. Livingston, F. Beaudry, P. Hélie, D. Frank, J. R. E. del Castillo, and E. Troncy. 2014. Assessing experimental visceral pain in dairy cattle: a pilot, prospective, blinded, randomized, and controlled study focusing on spinal pain proteomics. J. Dairy Sci. 97:2118-2134.
Riber, A. B., H. A. Van De Weerd, I. C. De Jong, and S. Steenfeldt. 2018. Review of environmental enrichment for broiler chickens. Poult. Sci. 97:378-396.

Shim, M. Y., A. B. Karnuah, N. B. Anthony, G. M. Pesti, and S. E. Aggrey. 2012. Genetics, the effects of broiler chicken growth rate on valgus, varus, and tibial dyschondroplasia. Poult. Sci. 91:62-65.

Siegford, J. M., J. Berezowski, S. K. Biswas, C. L. Daigle, S. G. Gebhardt-Henrich, C. E. Hernandez, S. Thurner, and M. J. Toscano. 2016. Assessing activity and location of individual laying hens in large groups using modern technology. Animals 6:10.

Tahamtani, F. M., I. J. Pedersen, and A. B. Riber. 2020. Effects of environmental complexity on welfare indicators of fast-growing broiler chickens. Poult. Sci. 99:21-29.

Tahamtani, F. M., I. J. Pedersen, C. Toinon, and A. B. Riber. 2018. Effects of environmental complexity on fearfulness and learning ability in fast growing broiler chickens. Appl. Anim. Behav. Sci. 207:49-56.

Tickle, P. G., J. R. Hutchinson, and J. R. Codd. 2018. Energy allocation and behaviour in the growing broiler chicken. Sci. Rep. 8:1-13.

Torrey, S., M. Mohammadigheisar, M. Nascimento dos Santos, D. Rothschild, L. C. Dawson, Z. Liu, E. G. Kiarie, A. M. Edwards, I. Mandell, N. Karrow, D. Tulpan, and T. M. Widowski. 2021. In pursuit of a better broiler: growth, efficiency, and mortality of 16 strains of broiler chickens. Poult. Sci 100:100955.

Vasdal, G., J. Vas, R. C. Newberry, and R. O. Moe. 2019. Effects of environmental enrichment on activity and lameness in commercial broiler production. J. Appl. Anim. Welf. Sci. 22:197-205.

Wallenbeck, A., S. Wilhelmsson, L. Jönsson, S. Gunnarsson, and J. Yngvesson. 2016. Behaviour in one fast-growing and one slowergrowing broiler (Gallus gallus domesticus) hybrid fed a high- or low-protein diet during a 10-week rearing period. Acta Agric. Scand. Anim. Sci. 66:168-176.

Weeks, C. A., T. D. Danbury, H. C. Davies, P. Hunt, and S. C. Kestin. 2000. The behaviour of broiler chickens and its modification by lameness. Appl. Anim. Behav. Sci. 67:111-125.

Weimer, S. L., A. Mauromoustakos, D. M. Karcher, and M. A. Erasmus. 2020. Differences in performance, body conformation, and welfare of conventional and slow-growing broiler chickens raised at 2 stocking densities. Poult. Sci. 99:4398-4407.

Wilhelmsson, S., J. Yngvesson, L. Jönsson, S. Gunnarsson, and A. Wallenbeck. 2019. Welfare Quality ${ }^{\circledR}$ assessment of a fast-growing and a slower-growing broiler hybrid, reared until 10 weeks and fed a low-protein, high-protein or mussel-meal diet. Livest. Sci. 219:71-79.

Zuidhof, M. J., B. L. Schneider, V. L. Carney, D. R. Korver, and F. E. Robinson. 2014. Growth, efficiency, and yield of commercial broilers from 1957, 1978, and 20051. Poult. Sci. 93:2970-2982. 